\title{
Microstructure and Mechanical Behaviour of Al/SiC/Agro-Waste RHA Hybrid Metal Matrix Composite
}

\author{
Shashi Prakash Dwivedi, Ashish Kumar Srivastava*, Nagendra Kumar Maurya, Rohit Sahu \\ G. L. Bajaj Institute of Technology \& Management, Greater Noida, Gautam Buddha Nagar, U.P. 201306, India
}

Corresponding Author Email: ashish.srivastava@glbitm.org

https://doi.org/10.18280/rcma.300107

Received: 18 September 2019

Accepted: 5 November 2019

\section{Keywords:}

hybrid composite, SiC, RHA, ductility, hardness, tensile strength

\begin{abstract}
In the present investigation, an attempt was made to utilize RHA in the development of aluminium based composite material. AA6061 alloy was melted in muffle furnace. Preheated RHA and SiC were added in the aluminium alloy. Composite material was fabricated by stir casting technique. Microstructure image showed proper wettability of reinforcement material with aluminium alloy matrix. Uniform distribution was observed of reinforcement particles in aluminium alloy. It has been observed that by using the RHA and $\mathrm{SiC}$ simultaneously in aluminium alloy, mechanical properties were improved significantly. However; toughness and ductility were reduced. Heat treatment of composite material was also carried out to observe the enhancement of mechanical property. Results showed that after the heat treatment process, mechanical properties were further improved.
\end{abstract}

\section{INTRODUCTION}

Nowadays, automobile industries as well as air craft industries are using light weight material with high strength material $[1,2]$. In the selection of material, it was observed that ferrous metals have high strength but its density is much high. However, non-ferrous metal such as aluminium have low density, but its strength is very low as compared to iron. However, by increasing the mechanical properties of aluminium, it can be used in the automobile and air craft industries [3, 4].

Aluminium alloy is now currently using in the development of composite material. Aluminium based composite materials are using in various industrial application $[5,6]$. Usually, composite is the combination of two or more than two materials. Here, one is matrix material and others are reinforcement materials. Reinforcement materials may be one or more than one. These reinforcement materials enhanced various properties of matrix material such as tensile strength, hardness etc. However, sometimes toughness and ductility are reduced [7-10].

Various authors have done their work on mechanical characterization and microstructural examinations of MMCs. Such as Srivastava et al. [11] has worked on the development of $\mathrm{A} 359 / \mathrm{B}_{4} \mathrm{C}$ MMCs by stir casting route. They discussed about the improvement in the mechanical properties. Idrisi and Deva [12] has fabricated the MMC by aluminum alloy reinforced with $\mathrm{SiC}$ particles. They observed that the mechanical properties were increases as the percentage contribution of SiC particles were increases. Milos et al. [13] worked on the development of composite by Al5083 alloy reinforced with $\mathrm{Al}_{2} \mathrm{O}_{3}$ and graphite. The weight \% and size of the reinforced particles was chosen as a variable to study the effect on mechanical properties. Further the tensile and compressive strength were studied by Idris et al. [14]. They also suggested that the liquid stirring processes is quite cheaper than the solid-state processing and liquid stirring has remarkable characteristics like improved wettability and chemical reaction between molten aluminum alloy and reinforcement particle. Meena et al. [15] has investigated the casting characteristics of $\mathrm{Al} 6063 / \mathrm{SiC}$ composite produced by mechanical stir casting. Weight percentage of reinforcement such as $5 \%, 10 \%, 15 \%$ and $20 \%$ were taken for the study. Srivastava et al. [16] reviewed the work related to development and characterization of MMCs published by various authors. They also discuss the merits and demerits of various fabricated composites. Dwivedi et al. [17] has discussed the thermal behavior and microstructural examination of Aluminum based composite reinforced with $\mathrm{SiC}$ and $\mathrm{MgO}$. Their results revels that the minimum expansion in dimension due to heat is observed at $5 \%$ of mixing of each reinforcements in the matrix alloy.

From the literature, it was observed that very few researchers are AA6061 matrix base composite material by using $\mathrm{SiC}$ as primary reinforcement material and Agro-waste RHA as secondary reinforcement material. Keeping these facts in the mind in the present investigation AA6061/SiC/RHA hybrid metal matrix composite material was developed. Further, mechanical properties of hybrid composite materials were investigated to observe the addition effect of SiC and RHA in AA6061 matrix material. Heat treatment process was also carried out to enhance further mechanical properties of hybrid composite material.

\section{MATERIALS AND METHODS}

\subsection{Matrix material}

In the present investigation, AA6061 aluminium alloy was 
taken as reinforcement material. AA6061 aluminium alloy was broadly used in various application among the all aluminium alloys. AA6061 materials are used in the fabrication of wings and fuselages in aircraft structures. It is used in the yacht construction. AA6061 alloys were also used in fabrication of chassis of the Audi A8. AA6061 alloy was also very good wieldable material.

\subsection{Reinforcement materials}

In this study, ceramic particle $\mathrm{SiC}$ was used as primary reinforcement material. $\mathrm{SiC}$ particles have good wettability characteristics with aluminium alloy $[18,19]$. Due to this reason, $\mathrm{SiC}$ is the most preferable ceramic particle with aluminium alloy. Agro-waste RHA (rice-husk ash) is agricultural waste materials which produce lots of soli pollution in agricultural land [20]. By utilizing this waste in the development of composite material, some pollution may be reduced. Further, by using RHA as secondary reinforcement material with AA6061 alloy, some mechanical properties can be improved.

\subsection{Development of hybrid composite material}

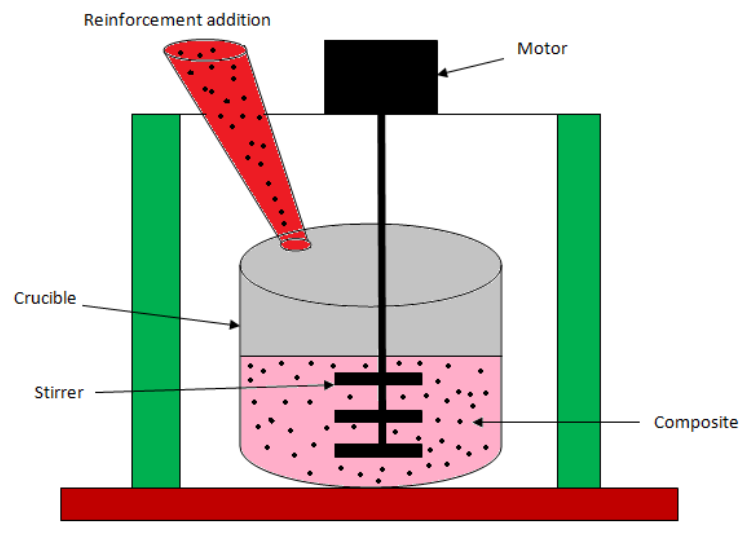

Figure 1. Schematic diagram of stir casting process [10]

Table 1. Composition selection

\begin{tabular}{|c|c|c|c|}
\hline $\begin{array}{l}\text { Sample } \\
\text { No. }\end{array}$ & Compositions & $\begin{array}{l}\text { Wt. \% of } \\
\text { SiC }\end{array}$ & $\begin{array}{c}\text { Wt. \% of } \\
\text { RHA }\end{array}$ \\
\hline 1 & $\begin{array}{c}\mathrm{AA} 6061+0 \% \mathrm{SiC}+0 \% \\
\text { RHA }\end{array}$ & $0 \%$ & $0 \%$ \\
\hline 2 & $\begin{array}{c}\mathrm{AA} 6061+15 \% \mathrm{SiC}+0 \% \\
\text { RHA }\end{array}$ & $15 \%$ & $0 \%$ \\
\hline 3 & $\begin{array}{c}\mathrm{AA} 6061+12.5 \% \mathrm{SiC}+ \\
2.5 \% \mathrm{RHA}\end{array}$ & $12.5 \%$ & $2.5 \%$ \\
\hline 4 & $\begin{array}{c}\mathrm{AA} 6061+10 \% \mathrm{SiC}+5 \% \\
\mathrm{RHA}\end{array}$ & $10 \%$ & $5 \%$ \\
\hline 5 & $\begin{array}{c}\mathrm{AA} 6061+7.5 \% \mathrm{SiC}+ \\
7.5 \% \mathrm{RHA}\end{array}$ & $7.5 \%$ & $7.5 \%$ \\
\hline 6 & $\begin{array}{c}\mathrm{AA} 6061+5 \% \mathrm{SiC}+10 \% \\
\mathrm{RHA}\end{array}$ & $5 \%$ & $10 \%$ \\
\hline 7 & $\begin{array}{c}\mathrm{AA} 6061+2.5 \% \mathrm{SiC}+ \\
12.5 \% \mathrm{RHA}\end{array}$ & $2.5 \%$ & $12.5 \%$ \\
\hline 8 & $\begin{array}{c}\mathrm{AA} 6061+0 \% \mathrm{SiC}+15 \% \\
\text { RHA }\end{array}$ & $0 \%$ & $15 \%$ \\
\hline
\end{tabular}

Figure 1 shows the line diagram of stir casting set-up. Hybrid metal matrix composites were fabricated by using the mechanical stir casting technique. First of all, AA6061 matrix material was melted in muffle furnace. Reinforcement particles $\mathrm{SiC}$ and $\mathrm{RHA}$ were preheated before mixing it in matrix material. Reinforcement materials were added in AA6061 matrix material at temperature $700^{\circ} \mathrm{C}$. Prepared composite material was removed from crucible after the solidification. Composition of hybrid composite material was shown in Table 1.

\section{RESULTS AND DISCUSSION}

\subsection{Microstructure analysis}

Figure 2 shows the microstructure image of AA6061/SiC/RHA hybrid metal matrix composite. Microstructure image shows some agglomeration of RHA particles inside the AA6061 matrix material. However, SiC particles were distributed uniformly inside the matrix material. From the microstructure image, it can be concluded that mechanical properties enhanced due to the presence of $\mathrm{SiC}$ and RHA in AA6061 matrix material.

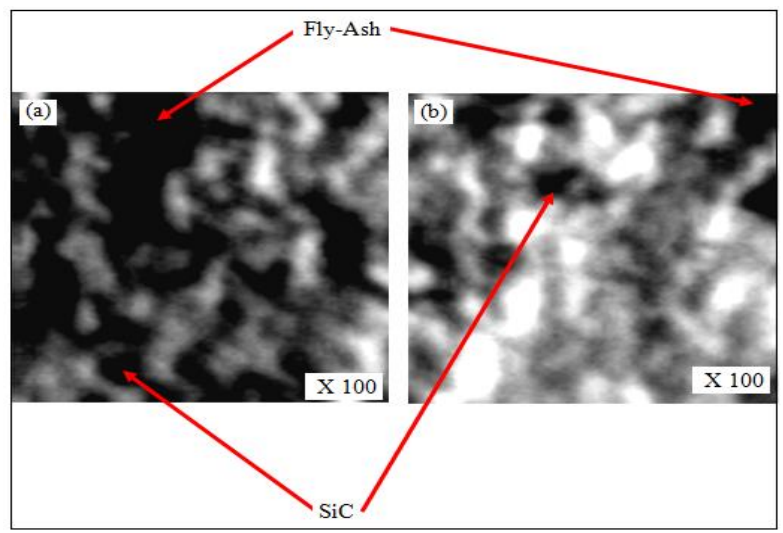

Figure 2. Microstructure of hybrid metal matrix composite

\subsection{Tensile strength analysis}

Figure 3 shows the microstructure image of AA6061/SiC/Agro-waste RHA hybrid metal matrix composite. Maximum tensile strength was found to be 165 MPa for composition AA6061+12.5\% SiC+2.5\% RHA hybrid metal matrix composite. Tensile strength of AA6061+12.5\% $\mathrm{SiC}+2.5 \%$ RHA hybrid metal matrix composite was further improved after the heat treatment process. Result showed that after the heat treatment process about $65.71 \%$ tensile strength was improved with respect to base AA6061 matrix material as shown in Figure 3. Enhancement of tensile strength of composite is due to the presence of hard phases in RHA such as $\mathrm{SiO}_{2}, \mathrm{CaO}, \mathrm{Fe}_{2} \mathrm{O}_{3}, \mathrm{~K}_{2} \mathrm{O}, \mathrm{TiO}_{2}, \mathrm{MnO}, \mathrm{CuO}$. Silicon carbide ( $\mathrm{SiC})$ was also fully responsible in enhancing the tensile strength of composite.

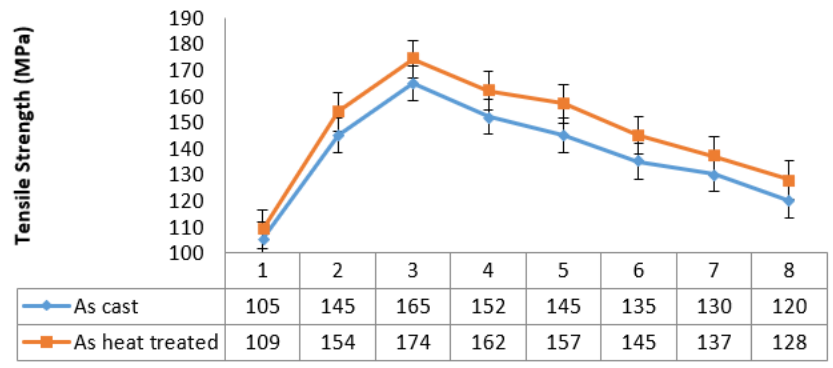

Figure 3. Tensile strength of hybrid metal matrix composite 


\subsection{Hardness}

Figure 4 shows the hardness of hybrid metal matrix composite material. Results showed that addition of ceramic particle enhanced the hardness of composite material. Maximum hardness was found to be $88 \mathrm{BHN}$ for composition AA6061+15\% SiC $+0 \%$ RHA. Hardness of the hybrid metal matrix composite was further improved after the heat treatment process. Results showed that after the heat treatment process, $95 \mathrm{BHN}$ was observed of AA6061+15\% SiC+0\% RHA composite material. Low porosity in the composite was fully responsible in the enhancement of hardness of AA6061+15\% SiC+0\% RHA composite. However, Silicon carbide is a very hard particle. Reinforcement of SiC particles in the AA6061 matrix material, improved the hardness significantly.

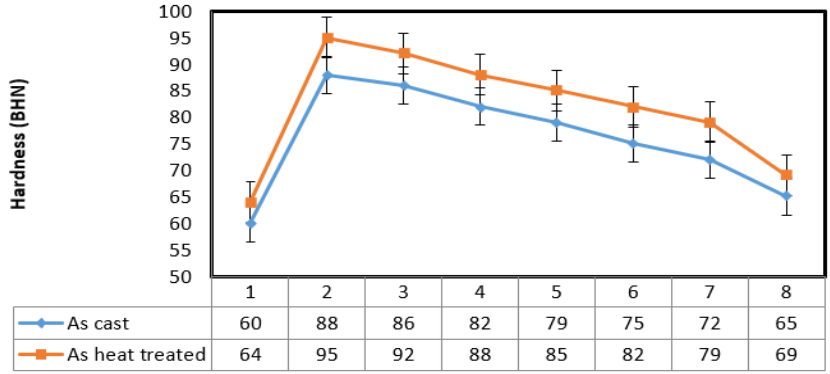

Figure 4. Hardness of hybrid metal matrix composite

\subsection{Fracture toughness}

Figure 5 shows the fracture toughness of hybrid metal matrix composite. Fracture toughness of hybrid composite material was continuously decreased by adding the $\mathrm{SiC}$ and RHA particles in AA6061 matrix material. However, fracture toughness was improved after the heat treatment process. Hard phases in RHA such as $\mathrm{SiO}_{2}, \mathrm{CaO}, \mathrm{Fe}_{2} \mathrm{O}_{3}, \mathrm{~K}_{2} \mathrm{O}, \mathrm{TiO}_{2}, \mathrm{MnO}$, $\mathrm{CuO}$ are always enhanced the tensile strength and hardness of composite. Presence of hard phases in composite material, energy required to cause a crack to grow to fracture decreases, resulting fracture toughness decreases.

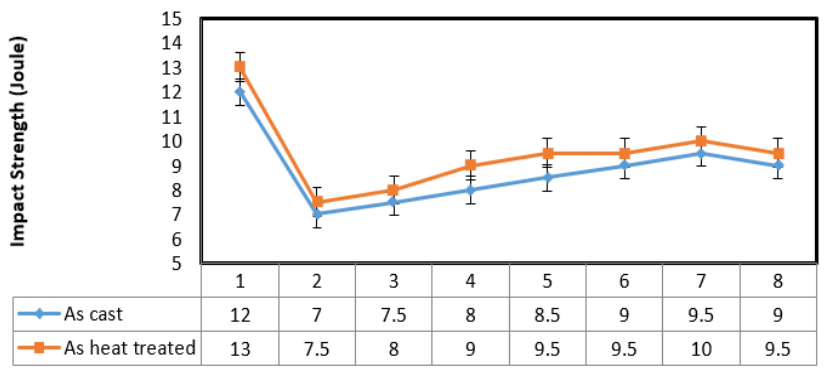

Figure 5. Toughness results of hybrid metal matrix composite

\subsection{Ductility (percentage elongation)}

Ductility of the composite material was identified by observing the percentage elongation of composite material. Percentage elongation was observed from the tensile samples of hybrid composite material. Figure 6 shows the ductility of hybrid composite material. Results showed that by adding the ceramic particle in AA6061 matrix material, ductility was continuously decreasing. When hard particles are added in the matrix material, deformation before fracture is reduced. Low deformation before fracture reduced the ductility of composite.

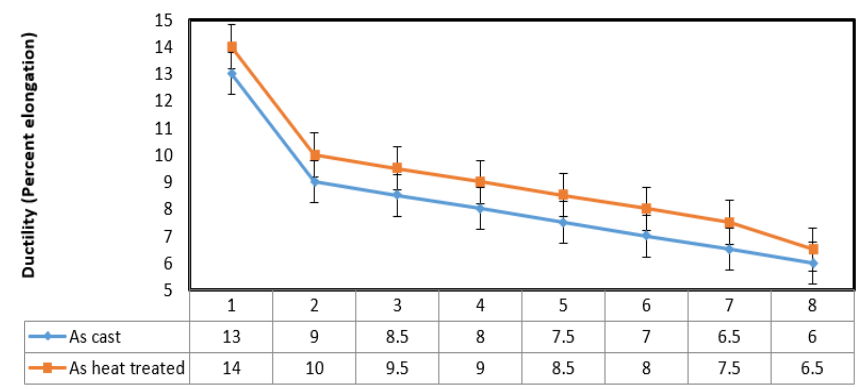

Figure 6. Ductility of hybrid metal matrix composite

\subsection{Corrosion behaviour}

The durability of the material in the moisture or acid surrounding is one of the most important factors in the selection of material for different application. Corrosion behaviour of the hybrid composite material reinforced with $\mathrm{SiC}$ and RHA has been observed to identify the reinforcement particle addition effect on aluminium alloy. Corrosion behaviour of the composite was observed in 3.5 wt. $\% \mathrm{NaCl}$ for 120 hours. Weight of each sample before the test was kept $15 \mathrm{gm}$. Corrosion behaviour of AA6061+7.5\% SiC+7.5\% RHA hybrid composite material observed before heat treatment and after heat treatment. Silicon Carbide is a ceramic particle. Addition of $\mathrm{SiC}$ particles in the aluminium alloy with minimum porosity reduced the weight loss of the aluminium based composite material. It has been observed that after the heat treatment process, weight loss of the composite material reduced as shown in Figure 7.

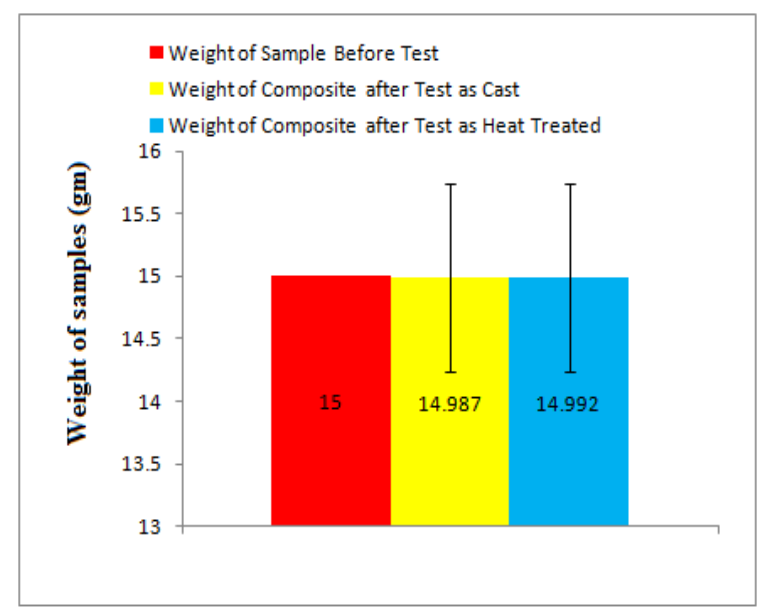

Figure 7. Corrosion behaviour of composite

\subsection{Thermal expansion behaviour}

Thermal Expansion Behaviour of hybrid composite material has been identified to observe the material durability in a hightemperature environment. Thermal expansion behaviour of $\mathrm{AA} 6061+7.5 \% \mathrm{SiC}+7.5 \% \mathrm{RHA}$ hybrid composite material as cast and as heat treated has been observed to identify the heat treatment effect on the composite material. The dimension of the sample has been kept $2500 \mathrm{~mm}^{3}(25$ X 10 X 10) before the test. Results showed that after the heat treatment process, thermal expansion of the composite material has been significantly improved (Figure 8). 


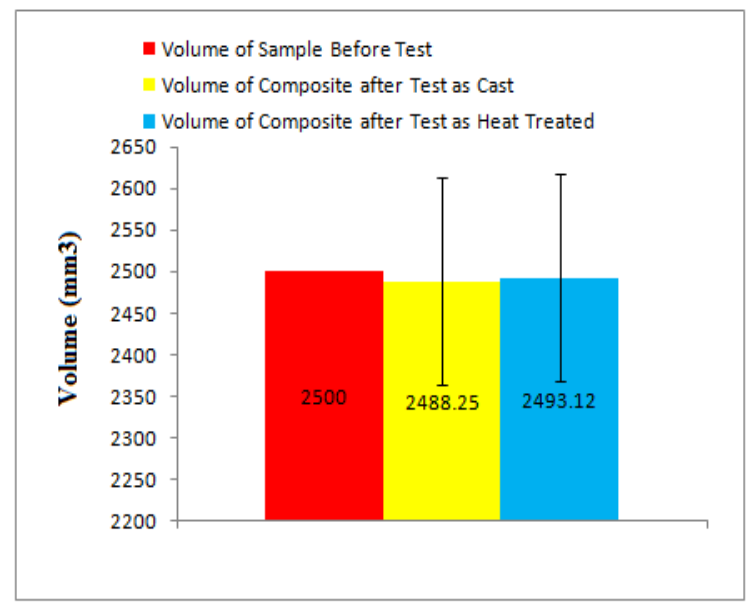

Figure 8. Thermal expansion behaviour of composite

\section{CONCLUSION}

Following conclusions may be drawn from the exhaust analysis.

1. Rice husk ash is an agricultural waste which produces soil pollution in agricultural land.

2. AA6061 matrix material was successfully developed by using $\mathrm{SiC}$ primary reinforcement material and RHA as secondary reinforcement material by using mechanical stir casting technique.

3. Results showed that by using $\mathrm{SiC}$ and RHA reinforcement material simultaneously, tensile strength and hardness were improved.

4. Ductility and toughness were reduced by adding the $\mathrm{SiC}$ and RHA reinforcement particles in AA6061 matrix material.

5. Mechanical properties of composite were improved after the heat treatment process.

6. It has been recommended for the future work that creep behaviour, fatigue behaviour, corrosion loss and thermal behaviour can be also observed of Al/SiC/Agro-waste RHA Hybrid Metal Matrix Composite

\section{REFERENCES}

[1] Palanivel, R., Dinaharan, I., Laubscher, R.F., Davim, P. J. (2016). Influence of boron nitride nanoparticles on microstructure and wear behavior of $\mathrm{AA} 6082 / \mathrm{TiB}_{2}$ hybrid aluminum composites synthesized by friction stir processing. Materials \& Design, 106: 195-204. https://doi.org/10.1016/j.matdes.2016.05.127

[2] Sangeetha, M., Prakash, S., Ramya, D. (2016). Wear properties estimation and characterization of coated ceramics with multiwall carbon nano tubes (MWCNT) reinforced in aluminium matrix composites. Materials Today: Proceedings, 3(6): 2537-2546. https://doi.org/10.1016/j.matpr.2016.04.173

[3] Dinaharan, I., Nelson, R., Vijay, S.J., Akinlabi, E.T. (2016). Microstructure and wear characterization of aluminum matrix composites reinforced with industrial waste fly ash particulates synthesized by friction stir processing. Materials Characterization, 118: 149-158. https://doi.org/10.1016/j.matchar.2016.05.017
[4] Pramanik, A. (2016). Effects of reinforcement on wear resistance of aluminum matrix composites. Transactions of Nonferrous Metals Society of China, 26: 348-358. https://doi.org/10.1016/S1003-6326(16)64125-0

[5] Yue, H.Y., Wang, B., Gao, X., Zhang, S.L., Lin, X.Y., Yao, L.H., Guo, E.J. (2017). Effect of interfacial modifying on the microstructures, mechanical properties and abrasive wear properties of aluminum borate whiskers reinforced 6061 Al composite. Journal of Alloys and Compounds, 692: 395-402. https://doi.org/10.1016/j.jallcom.2016.09.082

[6] Durmus, H.K., Meric, C. (2007). Age-hardening behavior of powder metallurgy AA2014 alloy. Materials \& Design, 28(3): 982-986. https://doi.org/10.1016/j.matdes.2005.11.022

[7] Senthilkumar, R., Arunkumar, N., Hussian, M.M. (2015). A comparative study on low cycle fatigue behaviour of nano and micro $\mathrm{Al}_{2} \mathrm{O}_{3}$ reinforced AA2014 particulate hybrid composites. Results in Physics, 5: 273-280. https://doi.org/10.1016/j.rinp.2015.09.004

[8] Ugender, S., Kumar, A., Reddy, A.S. (2014). Experimental investigation of tool geometry on mechanical properties of friction welding of AA2014 aluminium alloy. Procedia Materials Science, 5: 824-831. https://doi.org/10.1016/j.mspro.2014.07.334

[9] Kadaganchi, R., Gankidi, M.R., Gokhale, H. (2015). Optimization of process parameters of aluminum alloy AA 2014-T6 friction stir welds by response surface methodology. Defence Technology, 11(3): 209-219. https://doi.org/10.1016/j.dt.2015.03.003

[10] Dwivedi, S.P., Srivastava, A., Kumar. A., Nandana, B. (2017). Microstructure and mechanical behaviour of RHA and B4C reinforced aluminium alloy hybrid metal matrix composite. Indian Journal of Engineering \& Materials $\quad$ Sciences, 24: 133-140. https://doi.org/10.1016/j.matpr.2019.08.244

[11] Srivastava, A.K., Dixit, A.R., Tiwari, S. (2016). Investigation of microstructural and mechanical properties of metal matrix composite $\mathrm{A} 359 / \mathrm{B}_{4} \mathrm{C}$ through electromagnetic stir casting. Indian Journal of Engineering \& Materials Sciences, 23: 171-180.

[12] Idrisi, A.H., Deva, S. (2014). Development and testing of metal matrix composite by reinforcement of sic particles on Al 5XXX series alloy. International Journal of Engineering Research and Technology, 3(2): 1303-1309.

[13] Miloš, K., Jurić, I., Škorput, P. (2011). Aluminium-based composite materials in construction of transport means. Promet-Traffic \&Transportation, 23: 87-96.

[14] Idrisi, A.H., Singh, V.D., Saxena, B. (2014). Development and testing of aluminium 5083 alloy reinforced by silicon particles. International Journal of Scientific Research Engineering and Technology, 2: 697704.

[15] Meena, K., Manna, D.A., Banwait, D.S., Jaswanti, D. (2013). An analysis of mechanical properties of the developed Al/SiC-MMC's. American Journal of Mechanical Engineering, 1(1): 14-19. https://doi.org/10.12691/ajme-1-1-3

[16] Srivastava, A.K., Dixit, A.R., Tiwari, S. (2016). A review on the intensification of metal matrix composites and its nonconventional machining. Sci. Eng. of Compos. Materals, 25(2). https://doi.org/10.1515/secm-20150287

[17] Dwivedi, S., Sharma, S., Mishra, R. (2016). Mechanical 
and metallurgical

characterizations

of AA2014/Eggshells waste particulate metal matrix composite. International Journal of Precision Engineering and Manufacturing-green Technology, 3: 281-288. https://doi.org/10.1007/s40684-016-0036-0

[18] Dwivedi, S., Sharma, S., Mishra, R. (2016). Synthesis and mechanical behaviour of green metal matrix composites using waste eggshells as reinforcement material. Green Process Synth, 5(3): 275-282. https://doi.org/10.1515/gps-2016-0006

[19] Devaraju, A., Kumar, A., Kumaraswamy, A.,
Kotiveerachari, B. (2013). Influence of reinforcements $\left(\mathrm{SiC}\right.$ and $\mathrm{Al}_{2} \mathrm{O}_{3}$ ) and rotational speed on wear and mechanical properties of aluminum alloy 6061-T6 based surface hybrid composites produced via friction stir processing. Materials \& Design, 51: 331-341. https://doi.org/10.1016/j.matdes.2013.04.029

[20] Rohatgi, P.K., Kim, J.K., Gupta, N., Alaraj, S., Daoud, A. (2006). Compressive characteristics of A356/fly ash cenosphere composites synthesized by pressure infiltration technique. Composites: Part A, 37(3): 430437. https://doi.org/10.1016/j.compositesa.2005.05.047 